\title{
Region and Networks: multidimensional and multilevel approaches to analyze the health regionalization process in Brazil
}

\author{
Ana Luiza d'Ávila Viana 1 \\ Aylene Bousquat 2 \\ Maria Paula Ferreira 3 \\ Maria Alice Bezerra Cutrim 4 \\ Liza Yurie Teruya Uchimura 5 \\ Edgar Rodrigues Fusaro 6 \\ Miriam Regina de Souza 7 \\ Paulo Henrique dos Santos Mota 8 \\ Ana Paula Chancharulo de Morais Pereira 9 \\ Fabíola Lana lozzi 10 \\ Mariana Vercesi de Albuquerque 11 \\ 1,5,7,9 Departamento de Medicina Preventiva. Faculdade de Medicina. Universidade de São Paulo. São Paulo, SP, Brasil. \\ 2 Departamento de Política, Gestão e Saúde. Faculdade de Saúde Pública. Universidade de São Paulo. São Paulo, SP, Brasil. \\ 3 Fundação Sistema Estadual de Análise de Dados. São Paulo, SP. Email: mpferrei@seade.gov.br \\ 4 Fundação Sistema Estadual de Análise de Dados. São Paulo, SP, Brasil. \\ 6 Departamento Intersindical de Estatística e Estudos Econômicos. São Paulo, SP, Brasil. \\ 8 Departamento de Política, Gestão e Saúde. Faculdade de Saúde Pública. Universidade de São Paulo. Av. Dr. Arnaldo, 925. São Paulo, SP, Brasil. \\ CEP: 01.255-001. Email: paulohsmota@gmail.com \\ 10 Consultora. Email: lanafabiola@gmail.com \\ 11 Escola Nacional de Saúde Pública Sergio Arouca. Fundação Oswaldo Cruz. Rio de Janeiro, RJ, Brasil.
}

\begin{abstract}
Objectives: to present a methodology used by the Policy, Planning and Region Management research and the Health Care Networks in Brazil - the Regions and Networks research.

Methods: description of the analytical scheme in the process of choosing health regions and criteria to select cities and health units, instruments for collecting primary and secondary data and the indicators database, besides the regional typology elaborated for data analysis.

Results: the analytical scheme is based on the health policy analysis; policy, structure and organization were defined as the macro dimensions. For each one of these, sub-dimensions were defined. The questionnaire was elaborated by variables that were possible to analyze the regionalization process determinants. Five health regions were selected from the previously defined criteria.

Conclusions: the method allowed to establish attributes in the regionalization, constructed by specific components - integration, coordination and regulation. The multilevel approach was important because it portrayed different perceptions from the stakeholder managers and providers according to their bonds in the city, regional and state scenarios.
\end{abstract}

Key words Regionalization, Health Policy, Health systems 


\section{Introduction}

The regionalization process in Brazil has been around for a long period, taking it in consideration that it was proposed in the emergence of the Public Health System (SUS). However, there are still a few studies that provide an overview about its objectives, determinants and its links with the regional policies. Currently, there is a great effort to cover these gaps by specific publications on the theme and a series of national surveys and locations that are still in progress driven either for a more general discussion on the regional development as to reflect on the health area process. ${ }^{1}$

The challenges on the regionalization are an important topic in the health policies research in several countries, especially those that have as a universality goal. 2

Brown et al. 2 made effective review on the patients' trajectories through the health system and the providers' responses. The result is that both (patients and providers) are still frustrated. After all, the regionalization is not a process designed to provide such a change, since the coordination integration on services and care, even an efficient regulation. The authors claim that the regionalization can point to the integration and coordination of services and care, but should be improved with the introduction of innovations and policies, in order to improve the integration of the health system focusing on the patient. ${ }^{2}$

On the other hand, Fierlbeck 3 claims that the regionalization has served different political interests, since those facing the fiscal austerity, in order to weaken some health system stakeholders and strengthening others, even to conceal unpopular changes, transferring to other government bodies responsible for the actions of negative repercussions from a political point of view. ${ }^{3}$ The author even claims that the embedded regionalization process in long decentralization processes were operated many times by forces and coalitions built out of the sectoral policies and emerged for reasons beyond the sectoral agendas. It is important to emphasise that in the international literature, the processes of decentralization and regionalization are placed almost always as a single process, can be mistaken. The same author points out that for these reasons it is difficult to define the epidemiological impact and measure who has won or lost with the regionalization policy, as it can be done with a more specific health policies interventions. ${ }^{3}$

According to Fierlbeck, 3 the regionalization strategies fall into a category that Pawsons ${ }^{4}$ calls it the complex systems which is introduced between the complex systems; therefore, Marchal et al. 5 are correct when they say that is unlikely to make a general consistent and predictable theory on regionalization policies or any other complex sociopolitical intervention. Morin's words are quite appropriate when he says: "The more the problems become multidimensional, the greater is the inability to think in its multidimensionality."6

In Brazil, it can be stated that the regionalization policy in health was actually encouraged in the year 2000 , when it became quite clear that not all the cities could be self-sufficient in terms of health, and to think of a way to establish health regions and scales set for the provision of certain levels of care would mean rationality earnings and improvement in care.7

The regionalization policy in Brazil in recent decades can be separated in two moments: the Pacto pela Saúde (Health Pact) and the establishment of the Contrato Organizativo da Ação Pública da Saúde (COAP) (Organization Contract in Public Health Action), with intense discussion on the theme; and, at a later time, the institutional was void and the lack of innovation on the regionalization theme. The first moment covers what is being called by many authors, "the essay development phase"; and the second moment deals with an economic stagnation and a strong unstructure, or fiscal crisis of governmental entities and in addition to the institutional rupture by the Brazilian President's impediment, elected in 2014.8

The regionalization policy is set to be the great instrument of integration and coordination in networks and flow assistance, either in the development phase as the crisis period, produced a low impact at institutional level. This demonstrates that the external factors to the policy itself, although, are not the most prevalent and for sure has a great influence in this result. In other words, the coalition policies in the health sector and their interests should have influenced the strength of the developments and the directions of this process. Another element that deserves attention is the examination on the conditions of the States and its policies, which often came from the federal guidelines, or anticipating or leading the policy in another direction.

The non-consolidation of appropriate intergovernmental forums for the new demands of the regionalization process and to align health policies in three spheres of the government is one of the major obstacles for the regionalization to be executed. This should come as a surprise to many because it is precisely the mark of a social policy 
and, in specially health, which has been the involvement of the sub-national institutionalized authorities in implementing the policy. ${ }^{9}$

It is in this complex scenario that the Region and Networks research have proposed to study and disseminate knowledge about the peculiarities of the regionalization process in Brazil, considering it as the one that constitutes the health regions. Perhaps there is a hypothesis that the regional organization of services and health actions is an important instrument for the universal access in our country, having an enormous potential to decrease the huge socioeconomic inequalities and spacial that characterizes it. An effective regionalization process will contribute to the regional development and the improvement of health indicators. But for this purpose to achieve its goal, it is necessary to develop a solid institutional health regional. 10

The institutional health regional will have double functions: (i) to ensure the planning and coordination of the actions and services in the logic region, which would depend on new planning instruments; and (ii) unravel and confront the corporate interests involved in several provision of health services, which would depend on the establishment of a regional governance based on solidarity, democratization decision and intergovernmental cooperation.

The construction of the institutional health regional presupposes innovations on political, administrative, technological and cognitive and the development of a consistent regional ability of coordination from available resources. In addition, it is necessary to understand the governance as a cultural fact and not only as administrative contracts, which the final result may be the constitution of notion of the collective institutional concept in order to be enjoyed by everyone in a territorial space.

The creation of the institutional health regional and the universal access depends on: (i) From the point of view on politics, a regional planning with democratization, transparency and cooperation; (ii) from the point of view of the internal structure to the reduction of the barriers to access the system; (iii) from the point of view of the external structure of confrontation of the structural inequalities of the Brazilian regions (health) and inter and intra macroregional; and (iv) from the point of view of the organization, the expansion to access the system, by decreasing the waiting time, guaranteeing the completeness with equity and coordination of health networks.

Thus, the main objective of this research was to evaluate the organization, coordination and management processes involved in the regions and networks of healthcare, and its impact to improve access, effectiveness and efficiency of the actions and services in SUS. To understand the potential barriers to reduce inequality in the health universe in Brazil, it was necessary to identify the conditions that favors or makes it difficult to regionalize the States and shape the healthcare networks.

So, then, a research network was created involving 16 research institutions, distributed among the five macro-regions in Brazil: Universidade de São Paulo (USP), Universidade Estadual de Campinas (Unicamp), Universidade Federal de São Paulo (Unifesp), Faculdade de Ciências Médicas da Santa Casa de São Paulo (FCMSCSP), Instituto de Saúde da Secretaria Estadual de Saúde de São Paulo (IS/SES - SP), Hospital do Coração São Paulo (HCor), Escola Nacional de Saúde Pública da Fundação Oswaldo Cruz (ENSP-Fiocruz - RJ), Universidade Estadual do Rio de Janeiro (UERJ), Universidade Federal do Rio de Janeiro (UFRJ), Universidade Federal de Juiz de Fora (UFJF), Instituto Leônidas e Maria Deane (Fiocruz Manaus), Universidade Federal do Mato Grosso (UFMT), Universidade Federal da Bahia (UFBA), Instituto de Medicina Integral Professor Fernando Figueira (IMIP) Recife, Universidade Federal do Ceará (UFC) and Universidade Federal do Rio Grande do Sul (UFRGS). More than 100 professionals became involved in the work from several academic backgrounds such as university professors, researchers, statisticians, questioners, postgraduate students, representatives of the study centers, communication professionals and web-designers.

This article aims to present the methodological strategies used in the Regions and Networks research to operate the analysis of the regionalization process through multidimensional and multilevel approach. They will be presented as: the analytical scheme; the process of choosing the studied Health Regions, including the criteria to select the cities and the Basic Health Units (UBS); the elaborated analysis instruments (questionnaires, in depth interviews, therapeutic itineraries); in addition to the secondary data, the list of analyzed documents and the indicators' databank and the constructed regional typologies.

\section{Analytical Scheme}

The methodological focus of the research relied on the use of public policy instrumental analysis ${ }^{11}$ to understand the regionalization process in which the interest for its use on the possibilities to study the interactions among the State bureaucracy (policy 
managers at different governmental levels) and nonstate stakeholders (service providers), and the resources it mobilizes (linked to the morphology of the State and the institutions that provide services) to explain the policy design and its distributive results.

In the case of health, numerous decision-making processes occur in formal and informal arenas, often with different rules according to the Federal States and even within them, supported by the Federal Legislation, State and City, which grants the health policy a greater diversity in the designs of the implemented policy.

The interaction among the public and private State stakeholders is the definite form for health policy in Brazil (public funding, specially, provision of medium and high complexity outpatient and inpatient and examinations performed by private entities of various types). The question that guides the investigation understands to identify and discuss how their logics of action can contribute (or not) for a more equal health system (equal integration).

Therefore, it is to inquire which level of autonomy in the regionalization process of the health policy in relation to structural constraints, that is, the economy and politics. In order to take an account of this task, a multidimensional analysis was decided in which are added in three dimensions that can be explained, if not all, at least part of the regionalization process: policy, structure and organization.

The first dimension, referring to the political process itself, it seeks to identify the acting spaces, negotiation and conflict in the region; the processes and decision flow; the political conduct; and the functions carried out by the institutions in the decisions on health in the region. Moreover, it seeks to bring a description of the technological incorporation process and how it meets the regional decisions, including the weight of the judicialization in the process of technological incorporation in different regions of this study.

According to Lima et al.,12 the term governance emerged in 1960 and today it configures itself as a polysemic concept. The government processes are the biggest definers of terms, in which they were assigned to the following meanings: "structure or set of rules and institutions; specific policy production mode; a mechanism to force the cooperation and reduce the transaction costs; production strategy on conditions to govern. ${ }^{12}$ The governance redefines and expands the different forms of relation between the State and the society, or among different governments, private sector stakeholders and members of the society. 12
The second dimension, the Structure represents the availability and sufficiency of human resources, physical, financial, in addition to human resources recruitment forms and services present in the regionalization policy in each region. It was sought to identify the installed capacity, the availability and human resources recruitment and services.

The Organization dimension had the intention to identify the conformation criteria of the Redes de Assistência à Saúde (RAS) (Health Care Network), the planning, the management, the systemic integration between services, the regulation, the instruments for monitoring and evaluation and the population's access to health care. The description of the processes effectively put into practice to implement RAS is also included in this dimension. They were considered some important definitions on the mission and common goals of RAS, namely: they operate in a cooperative and interdependent; constantly exchange their resources; they are established without hierarchy among the points of health care, organizing a polyarchy form; imply a continuum of primary, secondary and tertiary care levels; call for an integral care to promotion and prevent actions, curative, caregivers, rehabilitation and palliative; working under the coordination of the Primary Health Care (APS); provide timely care at times and appropriate places in efficiently form and offering safe and effective services with available evidence; focusing on the complete care cycle of a health condition; have responsibilities of sanitary and economical unambiguous on its population; and should generate value for the population.

Considered these dimensions have at the same time different degrees of autonomy and interdependence aspects and only an integrated view on the set of dimensions allows to identify which problems are the most recurrent in each one of them separately and in what shape the dimensions can interfere, jointly, in the regionalization process.

On the other hand, it was necessary to define what levels of health care are the key for integral care: without a doubt, primary health care, networks care and health surveillance (VS) constitute structural elements of care in various health systems, the Emergency Care Network (RUE) was prioritized for analysis along with APS and the VS, once, in the current stage of implementing RAS in Brazil, it occupies a structuring place.

The analytical scheme research understands these three dimensions (political, structure and organization), which is characterized according to the conditions of the regional dynamics of health (regional governance of health; flows of demand and 
structuring of offering; primary health care in the regions and networks; health care networks and clinical management; human resources; and technological incorporation), which can be seen in Figure 1.

This study was approved by the Ethics Committee of the Faculdade de Medicina da Universidade de São Paulo, with the process number $071 / 15$, according to the standard of the National Health Council number 466/12.

\section{The choice process of health regions}

The health regions were selected to express the diversity of situations in socioeconomic, territorial and the existing health system in Brazil. For this purpose, three criteria were used: territorial-administrative, socioeconomic development and offering and health system complexity.

For the territorial-administrative criterion was considered necessary the presence of the five biggest Brazilian regions (North, Northeast, Midwest, South and Southeast). It was decided on at least one of the sample health regions characterized by attending the population in two States, an interstate region.

The identification of different health regions according to its characteristics of socioeconomic development and the offering and the health services complexity, charging for the elaboration of a typology of these same regions. The data sources used for the construction of this typology were: the Censo Demográfico 2010 (Population Census 2010), conducted by the Instituto Brasileiro de Geografia e Estatística (IBGE) (Brazilian Institute of Geography and Statistics); the Bancos de Dados do Sistema Único de Saúde (National Health Care System Database); available in the Datasus (www.datasus.gov.br); the Relação Anual de Informações Sociais (RAIS) (Annual Relation of Social Information), is available annually by the Ministry of Labor (www.mte.gov.br) and the Sistema de Contas Regionais do IBGE (Regional Billing System of IBGE).

Naturally, the units of analysis were the health regions considering the 438 regions, which comprise the 5,570 Brazilian cities, according to the Decreto 7508/11 (Decree number 7508/11). The factorial analysis and the groups/clusters analysis of indicators proceeded in the socioeconomic situation and offering and health services complexity in the regions. They were then identified in five Brazilian health regions groups, 13 that synthesize the socioeconomic inequality and offering health services in the regions of five groups: Group 1, formed by regions which their main feature is the low socioeco- nomic development; Group 2, by presenting average and high levels of socioeconomic development and low offering and local health service complexity; Group 3, health regions with average and high levels of socioeconomic development and offering of services; Group 4, by grouping regions with high socioeconomic development and average offering service; and Group 5, by regions with high socioeconomic development and high offering of services. With the exception of Group 2, the others are represented in the chosen Regions for the research field.

In addition, the chosen health regions were considered as: capitals in the federative unit; the presence of State boundary; the existence of medical college; presence of the city in the Quali-SUS.

The regions selected were: North-Barretos, in São Paulo; Baixada Cuiabana in Mato Grosso, Manaus, Entorno and Alto Rio Negro, in the Amazonas; Petrolina and Juazeiro, belong to PEBA network: Rede Interestadual de Atenção à Saúde do Vale do Médio São Francisco (Rede PEBA) (an Interstate Network on Health Care in the average Valley of São Francisco); and Carbonifera/Costa Doce, in Rio Grande do Sul. Petrolina/Juazeiro were considered as a region by the constitutional history as an important PEBA interstate network. On the completion of a pre-field in the North-Barretos region, a dynamic unified regional in the SouthBarretos region was observed, but for this reason, both regions were included and are considered a region for investigational purposes. In Table 1 shows the diversity of selected regions.

In each region, at least three cities were included for the implementation of the field, among of which consisted mandatory in the city pole region. The others were chosen intentionally, based on the number of health establishments, population input, the distance from the city polo and predominance in the articulation of regional policy.

In each region, a number of informants were interviewed belonging to three different multilevel: managers (city health secretaries and regional directors), service providers (hospitals, clinics and basic health units coordinators and among others) and the society (the City Health Councils) (Table 2).

In each city, an intentional sample of the Basic Health Units (UBSs) representing the diversity of the structured quality of the APS services were chosen. Therefore, a typology was developed of all the Brazilian UBSs built were based on the results of the Brazilian census of UBS infrastructure conducted in the process of the external assessment of cycle 1 of the PMAQ-AB. 14 
Figure 1

Analytical scheme with its dimensions and inter-relations, Region and Networks Research 2014.

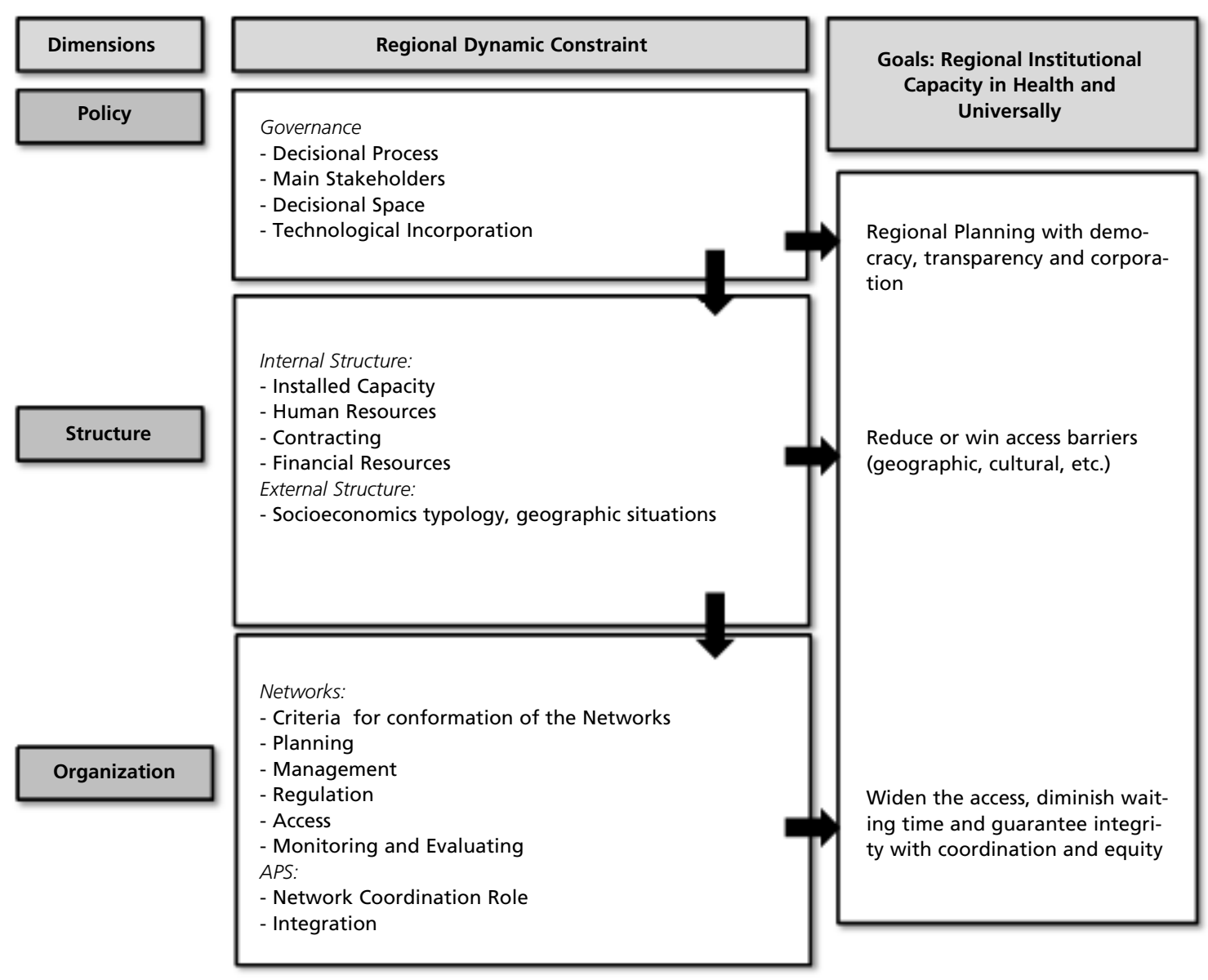




\section{Table 1}

Criteria to select researched regions, Region and Networks Research 2015.

Manaus, Entorno and Alto do Rio Negro (AM)

Petrolina (PE)/Juazeiro (BA)

Total sample of the health regions

North and South - Barretos (SP)

Carbonífera/Costa Doce (RS)

Baixada Cuiabana (MT)

The number of cities by health region

7 to 19

Population (2010) by health region

$140,721(\mathrm{~min})$ and $2,119,745(\max )$

Populational projections (2017)

Geometric Mean Rate of Annual Growth 2000/2010 (\%)

$147,892(\mathrm{~min})$ and $2,512,004(\mathrm{max})$

Regions of Group 1 (2016)

Regions of Group 2 (2016)

$0.29(\min )$ and $2.58(\max )$

Regions of Group 3 (2016)

Regions of Group 4 (2016)

Regions ofGroup 5 (2016)

Regions with Capitals of the FU

Quali-SUS Project Network

Regions in the International Border 2

Regions in the State boundary

Regions with RM and RIDE Cities 5

$\mathrm{RM}=$ Metropolitan Region; RIDE = Regional Integrated Economic Development.

Table 2

Number of interviewees by the type of respondent according to region, Region and Networks Research 2017.

\begin{tabular}{|c|c|c|c|c|c|}
\hline Type of Respondent & $\begin{array}{l}\text { North-Barretos/ } \\
\text { South-Barretos }\end{array}$ & $\begin{array}{l}\text { Petrolina/ } \\
\text { Juazeiro }\end{array}$ & $\begin{array}{l}\text { Baixada } \\
\text { Cuiabana }\end{array}$ & $\begin{array}{c}\text { Manaus, Entorno } \\
\text { and Alto Rio } \\
\text { Negro }\end{array}$ & $\begin{array}{c}\text { Carbonífera/ } \\
\text { Costa Doce }\end{array}$ \\
\hline Pharmaceutical Assistance & 5 & 7 & 5 & 3 & 5 \\
\hline City Manager & 5 & 6 & 3 & 3 & 3 \\
\hline Regional Manager & 1 & 2 & 2 & 1 & 2 \\
\hline City Provider & 12 & 16 & 11 & 8 & 11 \\
\hline Regional Provider & 6 & 13 & 5 & 9 & 5 \\
\hline RUE/SAMU & 4 & 7 & 3 & 5 & 3 \\
\hline Society & 1 & 5 & 5 & 4 & 5 \\
\hline Health Surveillance & 8 & 19 & 4 & 4 & 4 \\
\hline Total & 42 & 66 & 38 & 37 & 38 \\
\hline
\end{tabular}

RUE $=$ Emergency Care Network; SAMU = Physician Urgent Attendance Service . 


\section{The Analytical Instruments}

A large investment of the research team was the elaboration of a questionnaire to analyze the regionalization process in Brazil. A structured questionnaire was prepared in different stages, according to the following sub-dimensions: primary health care in the regions and networks in care, regional governance, networks on health care and clinical management, flows of demand and structuring the offering, human resources, technological incorporation and health surveillance. After this initial process, the issues were consolidated under the dimensions of Policy, Structure and Organization; followed by a consolidation list of interviewees (managers, providers, society). Repeated instruments reviews were performed by researchers until the final format of the questionnaire pilot.

The questionnaires incorporated questions about some specific problems considering tracers as proposed by Kessner et al.,15 based on the premise that some health problems can be particularly useful for the analysis of the provision of services and interactions among providers, users and society. The tracers included were the following: Diabetes Mellitus (DM), Hypertension (HAS) and Cerebrovascular Accident (CVA) for individual assistance; and Dengue and Tuberculosis for Health Surveillance. The questionnaire was composed of various issues, as noted, but each interviewee only answered the questions relevant to his/her level of performance/experience/insertion.

In the months of January and March in 2015, the pre-testing instruments were performed in three regions in different States. New reviews on the questionnaires were performed after the contribution of the tests, followed by the interviewees' question definition consolidating the instrument and the thematic content.

The questionnaire had 236 questions and 1126 variables in total. Table 3 shows the number of questions according to the type of interviewee and dimension. Also in-depth interviews were conducted with the State Health Secretaries, SES team manager and Health Councils.

In addition, we chose to perform the Itinerários Terapêuticos (IT) (Therapeutic Itineraries). The IT mapping is a potential methodology to analyze networks on health services which are little explored in the national literature. ${ }^{16}$ From Bellato et al., 17 perspective, the IT analysis is a technology assessment in health care. As a tool, it enables to identify the users' logic to obtain their own care, which intends the logic of services and provides little used information in the health services and systems management. ${ }^{17}$ Conill et al. 18 identified that the users' paths often do not respect the agreements and regulations previously established in the health services and action planning.

The IT completion in this present investigation aimed to learn the individual/family designed/travelled paths in seeking for care, allowing the flow of users to be verified with the normalized by the management of the studied health regions.

The paths travelled by the patients from the healthcare system have contributed for the understanding how the studied regions worked, as well as the care networks. It is worth noting that the IT also allowed to identify the out-of-pocket access the private services, often used by the population to supply gaps in the health services organization (example: payment of exams). The stroke (AVE) was chosen as a tracer. Then the IT was performed on patients hospitalized for CVA, with basic cause of hypertension (primary and secondary diagnosis at the Autorização de Internação Hospitalar (AIH) (Authorization for Hospital Admission), respectively) and who were discharged until six months prior of the interview (between one and seven months after hospital discharge)

The research also produced a specific study on the mobility of the medical professionals and the forms of organizing the offers of medical services in the five regions. Secondary data and semi-structured interviews were used with professionals from different areas and inserted in the health system, besides the representatives of corporative associations and the largest health plans present in the region.

Complementary studies on offering and the characteristics on health training in these regions and its impact on the regionalization process, as well as the scope on practices in the primary health care were all produced.

\section{Documentary analysis}

Another source of secondary data was documentary, which covered governments official documents especially those related to regionalization (Health State Plan, Regionalization Plan Director, Investment Plans, Management Reports, Constitutional Venture Terms, among others); the regulations (Laws, Resolutions and Decree), to the technical files and the records of SUS instant decision (Bipartite Inter-managers Commissions, Regional Inter-managers Commissions, State Health Council) produced during the study period. Other 
The number of issues by the type of respondent according to macro-dimension, Region and Networks Research 2015.

\begin{tabular}{lcccc}
\hline & Total & Policy & Structure & Organization \\
\cline { 2 - 5 } $\begin{array}{l}\text { Total of issues by } \\
\text { macro- dimension }\end{array}$ & 213 & 59 & 74 & 80 \\
\hline
\end{tabular}

Type of respondent

City Manager
Regional Manager
State manager
City Provider
Regional Provider
State provider
Society
RUE / SAMU
Pharmaceutical Assistance
Health Surveillance

$\begin{array}{cccc}150 & 53 & 44 & 53 \\ 150 & 53 & 44 & 53 \\ 127 & 51 & 44 & 32 \\ 73 & 13 & 31 & 29 \\ 24 & 17 & 7 & 0 \\ 5 & 5 & 0 & 0 \\ 5 & 5 & 0 & 0 \\ 42 & 7 & 18 & 17 \\ 10 & 10 & 0 & 0 \\ 43 & 6 & 16 & 21\end{array}$

RUE = Urgency and Emergency Network; SAMU= Physician Urgent Attendance Service .

types of documents were also prioritized, such as contracts and health plans with providers and instruments in the action market and the society in the health policy (for example, Popular Law project and actions mediated by the Public Ministry).

\section{The databank of indicators and typology of the} regions

Based on the secondary databanks, a databank of indicators and typology of regions were constructed through factorial analysis and of groups for the regions in Brazil. The maps and themes indicators can be viewed over the internet, on the research site (www.resbr.net.br). The indicators were grouped into the following categories: population and territory, typology of the region, urban infrastructure, economy, income and poverty, schooling, jobs and earnings, social vulnerability, Human Development Index (HDI), health conditions, morbidity, physical resources of the health system, human resources, SUS production, funding and coverage. The locations can be adjusted by data according to the total country, federative units, region and/or cities.

The research began in January 2014 and ended in May 2017. The field work in each of the regions studied lasted for a week. Only, in the region of Manaus and the fieldwork in Entorno were carried out in three stages of local specificities.

\section{Final Considerations}

As the regionalization is a complex phenomenon, it is advisable a systemic analysis, thus, as a public policy does not work obviously or linear. Therefore, the proposal for a multidimensional approach, adopted in the Regions and Networks research made it possible to articulate the analysis of policy, structure and organization dimensions. Variables were defined and allowed to verify the degree of influence in each of these dimensions in the regionalization process. In addition, allowing to establish the attributes of regionalization, constructed on the base of specific components - integration, coordination and regulation. Another important aspect was to adopt a multilevel approach interviewing managers and regional providers in City and State level.

The own phenomenon characteristic analyzed offers the opportunity to verify different arrangements in the regional networks organization on healthcare, indicating facilities and barriers.

Finally, limits can be pointed out to the methodology and the dependency on the interviewee's profile, whose answers may bring bias in the context (public or private official, employee), of their knowledge about the phenomenon studied, as well as, their inability to deal with all the constraints of the regionalization process. However, during the operationalization in the researched regions, the proposed 
method demonstrated to be appropriate and able to contribute for a better understanding of the possibili- ties in the constitution of regional networks within SUS.

\section{References}

1. Mello GA, Pereira APCM, Uchimura LYT, Iozzi FL, Demarzo MMP, Viana ALd'V. O processo de regionalização do SUS: revisão sistemática. Ciênc Saúde Coletiva. 2017; 22 (4): 1291-1310

2 Brown AD, Pisters WTP, Naylor D. Regionalization Does Not Equal Integration. Healthc Pap. 2016; 16 (1): 5-6.

3 Fierlbeck K. The Politics of Regionalization. Healthc Pap. 2016; 16 (1): 58-62.

4 Pawsons R. Evidence-Base Policy: a realist Perspective, London, UK: Sage; 2006

5 Marchal B, Westhorp G, Wong G, Van Belle S, Greenhalgh T, Kegels G, Pawson R. Realist RCTs of Complex Interventions - an Osymoron. Soc Sci Med. 2013; 94: 1248

6 Bosi MLM. Pesquisa qualitativa em saúde coletiva:panorama e desafios. Ciênc Saúde Coletiva. 2013, 17 (3): $575-86$

7 Viana AL, Lima LD. (Org.). Regionalização e relações federativas na política de saúde do Brasil. Rio de Janeiro: Contra capa Livraria Ltda., 2011, p. 11-24.

8 Bresser-Pereira, LC. Como sair do regime liberal de política econômica e da quase-estagnação desde 1990 . Estud Av. 2017; 31 (89): 7-22.

9 Pires RR e Gomide AD. Governança, Arranjos institucionais e capacidades estatais na implementação de políticas federais. In: Menicucci T e Gontijo JG organizadores. Gestão e Políticas públicas no cenário contemporâneo. Rio de Janeiro: Editora Fiocruz; 2016. p. 101-30.

10 Viana ALA. Região e Redes. Resumo Executivo: Política, planejamento e gestão das Regiões e Redes de Atenção à Saúde no Brasil. 2014. Disponível em http://www.resbr.net.br/a-pesquisa/resumo-executivo/

11 Donahue JD e Zeckhauser RJ. Public-private collaboration In Moran, M, Rein, M, Goodin, RE. Ed: The oxford handbook of public policy. Oxford university press; 2006. p. 496-527

Received on June 1st, 2017

Final version presented on August 18th, 2017

Approved on September 6th, 2017
12 Lima LD, Albuquerque MV, Scatena JHG. Quem governa e como se governam as regiões e redes de atenção à saúde no Brasil? Contribuições para o estudo da governança regional na saúde. Novos Caminhos, N.8. Pesquisa Política, Planejamento e Gestão das Regiões e Redes de Atenção à Saúde no Brasil (Região e Redes). 2016.

13 Viana ALD, Bousquat A, Pereira AP de CM, Uchimura LYT, Albuquerque MV de, Mota PH dos S, Demarzo MMP, Ferreira MP. Tipologia das regiões de saúde: condicionantes estruturais para a regionalização no Brasil. Saúde Soc. 2015; 24 (2): 413-22.

14 Giovanella L, Bousquat A, Fausto MCR, Fusaro E, Mendonça MHM, Gagno J. Tipologia das unidades básicas de saúde brasileiras. Novos Caminhos N. 5. Pesquisa Política, Planejamento e Gestão das Regiões e Redes de Atenção à Saúde no Brasil (Região e Redes). 2015.

15 Kessner DM, Kalk CE, Singer J. Assessing health qualitythe case for tracers. The New England journal of medicine. 1973; 288 (4): 189-94

16 Cabral A, Martinez-Hemáez A, Andrade E, Cherchiglia M. Itinerários terapêuticos: o estado da arte da produção científica no Brasil. Ciênc Saúde Coletiva. 2011; 16 (11): 443342 .

17 Bellato R, Araújo L, Castro P. O itinerário terapêutico como uma tecnologia avaliativa da integralidade em saúde. In: Pinheiro R, Silva Jr A, Mattos R, eds. Atenção básica e integralidade: contribuições para estudos de práticas avaliativas em saúde. Rio de Janeiro: IMS/UERJ; 2008. p.167-85.

18 Conill EM, Pires D, Sisson M, Oliveira M, Boing A, Fertonani H. O mix público-privado na utilização de serviços de saúde: um estudo dos itinerários terapêuticos de beneficiários do segmento de saúde suplementar brasileiro. Ciênc Saúde Coletiva. 2008; 13 (5): 1501-10. 